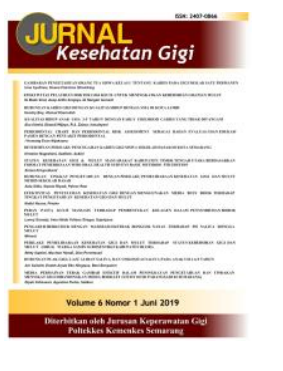

\title{
KUALITAS HIDUP ANAK USIA 3-5 TAHUN DENGAN EARLY CHILHOOD CARIES YANG TIDAK DITANGANI
}

\author{
Abu Hamid ${ }^{1}$ Dhandi Wijaya ${ }^{2}$ R.A. Zainur ${ }^{3}$ Ismalayani $^{4}$ \\ 1234 Jurusan Keperawatan Gigi Poltekkes Kemenkes Palembang, Indonesia
}

Corresponding author: Abu Hamid

Email: hamed_abu78@yahoo.co.id

Received: December 25 ${ }^{\text {th }}, 2018$; Revised: May 13 ${ }^{\text {th }}, 2019 ;$ Accepted: May $14^{\text {th }}, 2019$

\begin{abstract}
Early childhood caries (ECC), dental caries affecting the primary teeth in preschool aged children, is prevalent, especially among low social economic groups in developing countries. Treatment of ECC in developing country is almost nonexistent, so that it can cause more serious complications. Untreated ECC can affect on quality of life in preschool aged children. This cross-sectional study aim was to evaluate association between untreated ECC and quality of life of preschool children (aged 3-5 years). This cross sectional study was conducted on September-October 2018 in playgroups/kindergartens in Ilir Barat I Subdistrict, Palembang and consisted of 334 preschool children-parent pairs. Untreated ECC was assessed by PUFA/pufa index and preschool children's quality of life by ECOHIS instrument. Association between untreated ECC and quality of life were analyzed using the Fisher's exact test with 95\% CI. The result showed that ECC prevalence was $84.1 \%$ and the pufa was developed in $39.1 \%$ untreated ECC. There wasa significant association between untreated ECC and preschool children's quality of life $(\mathrm{p}<0,05)$. Children with ECC in this study had a good quality of life $(95.2 \%)$, sufficient (4.2\%), and bad (0.6\%). Similarly, parents who had children with ECC had good quality of life (86.6\%), sufficient $(10.8 \%)$, and bad (2.4\%). ECC that was not treated was statistically related to the quality of life of children and their parents $(\mathrm{p}<0.05)$. The conclusion of this study is that ECC that is not treated can affect the quality of life of children and their parents so that the ECC must be dealt with immediately.
\end{abstract}

Keywords: ECC; pufa; quality of life; ECOHIS

\section{Pendahuluan}

Karies gigi masih menjadi salah satu penyakit kronis terbanyak pada anak-anak yang mengganggu kualitas hidupnya. Early childhood caries (ECC) adalah karies gigi yang menyerang gigi primer pada anak usia prasekolah sangat sering terjadi, terutama pada anak-anak dalam kelompok sosial ekonomi rendah di negara-negara berkembang.
Duangthip D, dkk. (2017) melalui suatu literature review dari tiga database elektronik dari tahun 2006-2015 mendapatkan hasil prevalensi ECC pada anak usia 5-6 tahun di kawasan Asia Tenggara berkisar antara $25 \%$ sampai $95 \%$. Sedangkan prevalensi ECC di Indonesia menurut Sujitpto, dkk. (2014) sebesar 90,05\%. Angka prevalensi ECC di kawasan Asia Tenggara lebih tinggi dibandingkan prevalensi ECC pada anak usia 2-5 tahun di Amerika Serikat pada kurun 
waktu 1999 sampai 2004 sebesar 28\%. dan sebesar 72\% ECC tidak ditangani (Çolak H, dkk., 2013).

Penanganan ECC di negara-negara berkembang hampir tidak ada, sedangkan di negara maju seperti Amerika Serikat hanya 18\% ECC yang ditangani (Çolak H, dkk., 2013). Karies yang tidak ditangani terbukti dapat menyebabkan komplikasi yang lebih serius dibandingkan karies itu sendiri (Sudan J, dkk., 2018), seperti terjadinya pulpitis dan abses (Singhal \& Singla, 2018). Hasil penelitian Snehal, dkk. di India (2015) mendapatkan hasil 24\% ECC yang tidak ditangani akan berkembang menjadi keadaan klinis yang lebih buruk (pulpitis, ulserasi, fistula, dan abses). Monse dkk. (2010) memperkenalkan suatu indeks untuk menilai konsekuensi pada karies yang tidak ditangani, yaitu indeks PUFA/pufa (pulpitis, ulserasi, fistula, abses).

ECC yang tidak ditangani dapat menyebabkan nyeri, masalah dalam mengunyah, gangguan tidur, rasa kurang percaya diri, dan sering tidak masuk sekolah (Grund dkk., 2015). Pada keadaan yang lebih parah dapat menyebabkan malnutrisi, gangguan pertumbuhan, serta dapat memengaruhi kesehatan secara umum dan kualitas hidup anak (Singhal \& Singla, 2018; Naidu, dkk., 2016). Pengukuran kualitas hidup yang berhubungan dengan kesehatan mulut (oral healthrelated quality of life / OHRQoL) dalam beberapa tahun terakhir banyak mendapat perhatian, banyak tool yang dapat digunakan untuk menilai dampak kesehatan oral terhadap kualitas anak usia prasekolah, salah satunya adalah the Early Childhood Oral Health Impact Scale (ECOHIS) (Ramos-Jorge dkk., 2015) yang banyak digunakan untuk menilai dampak karies yang tidak ditangani terhadap kualitas hidup anak prasekolah (usia 3-5 tahun) (Ferreira dkk., 2017).

Tujuan penelitian ini adalah untuk mengetahui hubungan ECC yang tidak ditangani dengan kualitas hidup anak usia prasekolah.

\section{Metode Penelitian}

Jenis penelitian ini adalah penelitian potong lintang (cross sectional) untuk mengetahui hubungan ECC yang tidak ditangani dengan kualitas hidup anak usia prasekolah. Penelitian dilakukan pada bulan September sampai Oktober 2018 di playgroup atau TK di Kecamatan Ilir Barat I, Kota Palembang.

Kriteria inklusi penelitian ini adalah anak usia 3-5 tahun di playgroup atau TK di Kecamatan
Ilir Barat I, Kota Palembang, sedangkan kriteria eksklusinya adalah anak menderita penyakit sistemik, kelainan pskiatrik, sindrom kongenital, dan kelainan mukosa mulut, serta orang tua menolak berpartisipasi atau anak tidak kooperatif. Jumlah sampel sebanyak 334 pasang anak prasekolah dan orang tua/walinya yang dipilih secara purposive sampling.

ECC yang tidak ditangani dinilai menggunakan indeks PUFA/pufa dengan menilai adanya keterlibatan pulpa (P/p), adanya ulserasi $(\mathrm{U} / \mathrm{u})$ karena sisa akar, adanya fistel $(\mathrm{F} / \mathrm{f})$, dan apakah sudah terjadi abses (A/a).

Kualitas hidup anak prasekolah dinilai menggunakan instrumen ECOHIS yang telah diterjemahkan ke dalam bahasa Indonesia yang diuji validitas dan realibilitasnya menggunakan Pearson correlation dan uji korelasi Cronbach's alpha. Kuesioner terdiri dari 9 item pertanyaan untuk ranah anak dan 4 item pertanyaan untuk ranah orang tua, dan diisi berdasarkan pengalaman orang tua dan anaknya dalam 3 (tiga) bulan terakhir. Respon atau jawaban dibagi dalam 6 kategori dengan skor 0 sampai 5 , yaitu $0=$ tidak pernah; $1=$ sangat jarang; $2=$ kadang-kadang; $3=$ sering; $4=$ sangat sering; $5=$ tidak tahu. Skor jawaban "tidak tahu" tidak dimasukkan dalam penghitungan, sehingga rentang skor ranah berkisar antara 0 sampai 36 dan rentang skor ranah orang tua antara 0 sampai 16. Ranah anak dikategorikan menjadi: Baik (skor 0-9), Cukup (skor 10-18), Buruk (skor 19-27), dan Sangat Buruk (skor 28-36), sedangkan ranah keluarga dikategorikan menjadi: Baik (skor 0-4), Cukup (skor 5-8), Buruk (skor 9-12), dan Sangat Buruk (skor 13-16). Hubungan ECC yang tidak ditangani dengan kualitas hidup anak usia prasekolah dianalisis menggunakan uji Fisher exact dengan interval kepercayaan 95\%.

Penelitian ini telah mendapat rekomendasi persetujuan etik dari Komite Etik Penelitian Kesehatan Poltekkes Makassar Nomor: 665/KEPK-PTKMKS/VIII.2018, tanggal 31 Agustus 2018.

\section{Hasil dan Pembahasan}

Dari 334 anak prasekolah yang menjadi sampel penelitian, 164 anak $(49,1 \%)$ berjenis kelamin laki-laki dan 170 anak $(50,9 \%)$ perempuan, dengan rata-rata usia 4,695 tahun (SD 0.5033). 
Tabel 1

Rata-rata Indeks deft $(\mathrm{n}=281)$

\begin{tabular}{lcc}
\hline \multicolumn{1}{c}{ Indeks deft } & Rata-rata & SD \\
\hline Decay (d) & 6,67 & 5,146 \\
Extraction (e) & 0,04 & 0,265 \\
Filling (f) & 0,05 & 0,324 \\
Total (t) & 8,04 & 4,638 \\
\hline
\end{tabular}

Sebanyak 281 anak $(84,1 \%)$ menderita karies, dengan rata-rata indeks deft 8,04 (SD 4,638). Tabel 1 menunjukkan bahwa sebagian besar ECC tidak ditangani, rata-rata ekstraksi hanya sebesar $4 \%$ dan tumpatan sebesar $5 \%$. Hasil ini lebih tinggi dibandingkan ECC yang tidak ditangani di Amerika Serikat, yaitu sebesar $72 \%$ (Çolak H, dkk., 2013).

Tabel 2

Distribusi pufa $(\mathrm{n}=281)$

\begin{tabular}{lcc}
\hline & Jumlah & \% \\
\hline pufa & & \\
Tidak & 171 & 60,9 \\
Ya & 110 & 39,1 \\
\hline Jenis pufa & & \\
Pulpitis (p) & 88 & 26,3 \\
Ulserasi (u) & 15 & 4,5 \\
Fistula (f) & 5 & 1,5 \\
Abses (a) & 2 & 0,6 \\
\hline
\end{tabular}

Pada 281 sampel penelitian yang menderita ECC ditemukan prevalensi pufa sebesar $39,1 \%$, hasil ini lebih tinggi dibandingkan hasil penelitian Snehal, dkk. (2015) sebesar 24\%. Komplikasi yang terbanyak adalah pulpitis (26,3\%), yang menunjukkan bahwa sebagian besar pufa masih pada tahap awal sehingga diperlukan penanganan dengan segera untuk mencegah timbulnya komplikasi lebih lanjut (Tabel 2).

Tabel 3.

Kualitas Hidup Anak dan Keluarga $(\mathrm{n}=334)$

\begin{tabular}{lcc}
\hline \multicolumn{1}{c}{ Kualitas Hidup } & Jumlah & \% \\
\hline Ranah anak & & \\
Baik & 318 & 95,2 \\
Cukup & 14 & 4,2 \\
Buruk & 2 & 0,6 \\
Sangat buruk & 0 & 0 \\
\hline Ranah Orang Tua & & \\
Baik & 290 & 86,8 \\
Cukup & 36 & 10,8 \\
Buruk & 8 & 2,4 \\
Sangat buruk & 0 & 0 \\
\hline
\end{tabular}

Dari Tabel 3 terlihat bahwa sebagian besar kualitas hidup anak dan keluarga dalam kategori baik, masing-masing sebesar $95,2 \%$ dan $86,8 \%$, dan tidak ada kualitas hidup dalam kategori sangat buruk baik pada ranah anak maupun keluarga.

Tabel 5

Hubungan Tingkat Keparahan Karies dengan Kualitas Hidup Anak $(\mathrm{n}=334)$

\begin{tabular}{|c|c|c|c|c|c|c|}
\hline & \multicolumn{4}{|c|}{ Kualitas Hidup Anak } & \multirow[b]{2}{*}{$\begin{array}{c}\text { Nilai } \\
\left.\mathbf{p}^{*}\right)\end{array}$} \\
\hline & & Baik & $\begin{array}{c}\text { Cuk } \\
\text { up }\end{array}$ & $\begin{array}{c}\text { Buru } \\
\mathbf{k}\end{array}$ & $\begin{array}{c}\text { Tota } \\
\text { l }\end{array}$ & \\
\hline \multirow{5}{*}{$\begin{array}{c}\text { p } \\
\text { uf } \\
\text { a }\end{array}$} & $\mathbf{T i}$ & & & & & 0,03 \\
\hline & d & 219 & 4 & 1 & 22 & \\
\hline & $\begin{array}{l}\mathbf{a} \\
\mathbf{k}\end{array}$ & $(97,8)$ & $(1,8)$ & $(0,4)$ & (100) & \\
\hline & $\mathbf{Y}$ & 99 & 10 & 1 & 110 & \\
\hline & $\mathbf{a}$ & $(90,0)$ & $(9,1)$ & $(0,9)$ & (100) & \\
\hline \multicolumn{2}{|c|}{ Total } & $\begin{array}{c}318 \\
(95,2)\end{array}$ & $\begin{array}{c}14 \\
(4,2)\end{array}$ & $\begin{array}{c}2 \\
(0,6)\end{array}$ & $\begin{array}{c}334 \\
(100)\end{array}$ & \\
\hline
\end{tabular}

*) Uji Fisher exact

Tabel 5 menunjukkan bahwa proporsi anak dengan pufa yang memiliki kualitas hidup baik lebih kecil dibandingkan anak tanpa pufa $(90 \%$ berbanding 97,8\%), sedangkan proporsi anak dengan pufa yang memiliki kualitas hidup cukup baik dan buruk lebih besar dibandingkan anak tanpa pufa (masing-masing 9,1\% berbanding 1,8\% dan $0,9 \%$ berbanding $0,4 \%$ ). Ditemukan hubungan yang bermakna secara statistik antara skor pufa dengan kualitas hidup anak $(\mathrm{p}=0,03)$.

Tabel 6

Hubungan Tingkat Keparahan Karies dengan Kualitas Hidup Orang Tua $(n=334)$

\begin{tabular}{|c|c|c|c|c|c|c|}
\hline & \multicolumn{4}{|c|}{ Kualitas Hidup Orang Tua } & \multirow[b]{2}{*}{$\begin{array}{c}\text { Nilai } \\
\left.\mathbf{p}^{*}\right)\end{array}$} \\
\hline & & Baik & $\begin{array}{c}\text { Cuk } \\
\text { up }\end{array}$ & $\begin{array}{c}\text { Buru } \\
\mathbf{k}\end{array}$ & Total & \\
\hline \multirow{2}{*}{$\begin{array}{c}\text { p } \\
\text { uf } \\
\text { a }\end{array}$} & $\begin{array}{l}\mathbf{T i} \\
\mathbf{d} \\
\mathbf{a} \\
\mathbf{k} \\
\end{array}$ & $\begin{array}{c}207 \\
(92,4 \\
)\end{array}$ & $\begin{array}{c}14 \\
(6,3)\end{array}$ & $\begin{array}{c}3 \\
(1,3)\end{array}$ & $\begin{array}{c}224 \\
(100)\end{array}$ & 0,00 \\
\hline & $\begin{array}{l}\mathbf{Y} \\
\mathbf{a}\end{array}$ & $\begin{array}{c}83 \\
(75,5 \\
\quad \\
\end{array}$ & $\begin{array}{c}22 \\
(20,0 \\
)\end{array}$ & $\begin{array}{c}5 \\
(4,5)\end{array}$ & $\begin{array}{c}110 \\
(100)\end{array}$ & \\
\hline \multicolumn{2}{|c|}{ Total } & $\begin{array}{c}290 \\
(86,8 \\
\quad\end{array}$ & $\begin{array}{c}36 \\
(10,8 \\
\quad)\end{array}$ & $\begin{array}{c}8 \\
(2,4)\end{array}$ & $\begin{array}{c}334 \\
(100)\end{array}$ & \\
\hline
\end{tabular}

*) Uji Fisher exact 
Tabel 6. menunjukkan bahwa proporsi orang tua yang anaknya mengalami pufa yang memiliki kualitas hidup baik lebih kecil dibandingkan orang tua yang anaknya tanpa pufa $(75,5 \%$ berbanding $92,4 \%$ ), sedangkan proporsi orang tua yang anaknya mengalami pufa yang memiliki kualitas hidup cukup baik dan buruk lebih besar dibandingkan orang tua yang anaknya tanpa pufa (masing-masing 20\% berbanding 6,3\% dan 4,5\% berbanding $1,3 \%$ ). Ditemukan hubungan yang bermakna secara statistik antara skor pufa dengan kualitas hidup orang tua atau keluarga $(\mathrm{p}=0,00)$.

Tabel 5 dan 6 menunjukkan bahwa dampak pufa pada anak cenderung lebih berpengaruh terhadap kualitas hidup orang tua dan keluarganya dibandingkan dengan kualitas hidup anak. Hasil yang serupa juga didapatkan oleh Nemati dkk. (2016) di Iran, yang menyimpulkan bahwa efek kesehatan oral pada anak lebih besar pada orang tua dibandingkan anak.

Karies merupakan penyakit multifaktorial yang berefek tidak hanya pada saat seseorang makan dan pada kebersihan rongga mulut, tetapi juga memengaruhi standar kehidupan mereka. Anak-anak dengan pengalaman karies gigi yang lebih banyak memiliki dampak lebih tinggi terhadap kualitas hidup mereka, karena adanya rasa nyeri pada rongga mulutnya (Barbosa, 2008).

Menurut Dumitrache (2009), anak-anak yang menderita pulpitis, ulserasi, fistula, dan abses (pufa) akibat ECC, memiliki kualitas hidup anak dan keluarga yang lebih buruk dibandingkan yang tidak mengalami pufa. Lebih lanjut, kerusakan pada gigi yang parah diketahui dapat memengaruhi status gizi, pertumbuhan, dan berat badan anak secara negatif (Shankeswari, 2013).

\section{Kesimpulan}

Prevalensi ECC pada penelitian ini sebesar $84,1 \%$ dan lebih dari $90 \%$ tidak ditangani, $39,1 \%$ ECC berlanjut menjadi keadaan klinis yang lebih buruk, yaitu terjadinya komplikasi berupa pufa. ECC yang tidak ditangani berhubungan secara statistik dengan kualitas hidup anak dan kualitas hidup orang tua/keluarga.

\section{Daftar Pustaka}

[1] Barbosa TS, Gaviao MBD. Oral health-related quality of life in children: Part II. Effects of clinical oral health status. A systematic review. Int J Dent Hygiene 2008; 6: 100-7. Lopes RM, Domingues GG, Junqueira SR,
Araujo ME, Frias AC. Conditional factors for untreated caries in 12-year-old children in the city of Sao Paolo. Braz Oral Res 2013; 27(4): 376-81.

[2] Çolak H, Dülgergil ÇT, Dalli M, \& Hamidi MM. Early childhood caries update: a review of cause, diagnoses, and treatments. JNSBM 2013 4:29-38.

[3] Duangthip D, Gao SS, Man Lo EC, and Chun Hung Chu. 2017. Early childhood caries among 5- to 6-year-old children in Southeast Asia. IDJ 67:98-106.

[4] Dumitrache MA, Comes C, Teodorescu E, Dumitrascu L, Cuculescu M, Ionescu E. Life quality related to oral health of school children from Bucharest. Romanian $J$ of Bioethics 2009; 7: 169-78.

[5] Ferreira MC, Ramos-Jorge ML, Marques LS, \& Ferreira FO. 2017. Dental caries and quality of life of preschool children: discriminant validity of the ECOHIS. Braz. Oral Res. [Online] 31:1-10. Tersedia dari: http://doi.org/10.1590/1807-3107BOR-2017 [Diunduh 29 Juli 2018]

[6] Grund K, Goddon I, Schüler IM, Lehmann T, \& Heinrich-Weltzien R. 2015. Clinical consequences of untreated dental caries in German 5- and 8-year-olds. BMC Oral Health [Online] 15:1-11. Tersedia dari: doi 10.1186/s12903-015-0121-8 [Diunduh 29 Juli 2018]

[7] Monse B, Heinrich-Weltzien R, Benzian H, Holmgren C, \& van Palenstein Helderman W. 2010. PUFA - An index of clinical consequences of untreated dental caries. Community Dent Oral Epidemiol 38:77-82.

[8] Naidu R, Nunn J, \& Donnelly-Swift E. 2016. Oral health-related quality of life and early childhood caries among preschool children in Trinidad. BMC Oral Health [Online] 16:1-9. Tersedia dari: doi 10.1186/s12903-016-03247 [Diunduh 29 Juli 2018]

[9] Nemati S, Ghasempour M, \& Khafri S. 2016. Impact of oral and dental health on quality of life in Iranian preschool children and their families. Ephysician [Online] 8:3296-3301. Tersedia dari: doi 10.19082/3296 [Diunduh 29 Juli 2018]

[10] Ramos-Jorge J, Alencar BM, Pordeus IA, Soares MEC, Marques LS, Ramos-Jorge ML, \& Paiva SM. 2015. Impact of dental caries on quality of life among preschool children: 
emphasis on the type of tooth and stages of progression. Eur J Oral Sci 123:88-95.

[11] Sankeshwari RM, Ankola AV, Tangade PS, Hebbal MI. Association of socio-economic status and dietary habits with early childhood caries among 3- to 5- year-old children of Belgaum city. Eur Arch Paediatr Dent 2013; 14: 147-53.

[12] Singhal DK \& Singla N. 2018. severity and clinical consequences of untreated dental caries using PUFA index among schoolchildren in Udupi Taluk, India. India. $J$ Orofac Sci 10: 19-23.

[13] Snehal P, Shivakumar KM, Hathiwala S, Raj Srinivasan S, \& Khatri S. 2015. Prevalence of untreated dental caries among the preschool children of Western Maharashtra. J. Dent. Oral Hyg. 7:175-178.

[14] Sudan J, Sogi GM, \& Veeresha LK. 2018. Assessing clinical sequelae of untreated caries among 5-, 12-, and 15-year-old school children in ambala district: a cross-sectional study. J Indian Soc Pedod Prev Dent 36:1520.

[15] Sutjipto RW, Herawati, \& Kuntari S. 2014. Prevalensi early childhood caries dan severe early childhood caries pada anak prasekolah di Gunung Anyar Surabaya. Dent. J. 7:186189. 